\title{
Enhanced Incentive Motivation for Sucrose-Paired Cues in Adolescent Rats: Possible Roles for Dopamine and Opioid Systems
}

\author{
Christie L Burton*, ${ }^{*, 2}$, Kevin Noble ${ }^{2}$ and Paul J Fletcher ${ }^{1,2,3}$ \\ 'Department of Psychology, University of Toronto, Toronto, ON, Canada; ${ }^{2}$ Department of Neuroscience, Section of Biopsychology, Centre for \\ Addiction and Mental Health, Toronto, ON, Canada and ${ }^{3}$ Department of Psychiatry, University of Toronto, Toronto, ON, Canada
}

\begin{abstract}
Vulnerability to the effects of drugs of abuse during adolescence may be related to altered incentive motivation, a process believed to be important in addiction. Incentive motivation can be seen when a neutral stimulus acquires motivational properties through repeated association with a primary reinforcer. We compared adolescent (postnatal day (PND) 24-50) and adult ( $>$ PND 70) rats on a measure of incentive motivation: responding for a conditioned reinforcer (CR). Rats learned to associate the delivery of $0.1 \mathrm{ml}$ of $10 \%$ sucrose with a conditioned stimulus (CS; light and tone); 30 pairings per day were given over 14 days. Then, we measured responding on a lever delivering the CS (now a CR) after injections of amphetamine $(0,0.25$ or $0.5 \mathrm{mg} / \mathrm{kg}$ ). We also examined responding for CR when the CS and sucrose were paired or unpaired during conditioning, and responding for the primary reinforcer (I0\% sucrose) in control experiments. Finally, we examined the effects of $D_{1}$ and $D_{2}$ dopamine receptor antagonists ( $\mathrm{SCH} 39166$ and eticlopride, respectively) and an opioid receptor antagonist (naltrexone) on responding for a CR in adolescent rats. Adolescents but not adults acquired responding for a $C R$, but adolescents responded less than adults for the primary reinforcer. Responding for a CR depended upon the pairing of the CS and sucrose during conditioning. Both dopamine and opioid receptor antagonists reduced responding for the CR. Therefore, incentive motivation may be enhanced in adolescents compared with adults, and incentive motivation may be mediated in part by both dopamine and opioid systems.

Neuropsychopharmacology (20II) 36, I63 I-1643; doi:10.1038/npp.201 I.44; published online 20 April 20I I
\end{abstract}

Keywords: adolescence; incentive motivation; conditioned reinforcer; dopamine

\section{INTRODUCTION}

Adolescents may be more vulnerable to the effects of drugs abuse, but the issue of what confers this vulnerability remains unresolved (Schramm-Sapyta et al, 2009; Spear, 2000). During this developmental period, many factors linked to drug abuse and addiction converge. Adolescents are considered to be prone to sensation-seeking and risky behavior, which may be, in part, the result of altered reward processing (Doremus-Fitzwater et al, 2010; Ernst et al, 2009; Spear, 2000). Although understanding how rewards themselves are processed during adolescence is important, another critical question is how do adolescents process and respond to reward paired-stimuli, particularly in the context of substance abuse. According to the incentive

\footnotetext{
*Correspondence: CL Burton, Department of Psychology, Centre of Addiction and Mental Health, University of Toronto, 250 College Street, Toronto, Canada, ON M5T IR8, Tel: + 4165358501 × 4896, Fax: + 416979 6942, E-mail: c.burton@utoronto.ca

Received 17 December 2010; revised 16 February 2011; accepted 17 February 2011
}

salience theory of addiction (Robinson and Berridge, 1993, 2001), cues paired with drugs contribute prominently to the development, maintenance, and reinstatement of drug abuse. One process that has an important role in attributing salience to such drug-paired cues is incentive motivation.

Incentive motivation is, in part, the process where initially neutral environmental stimuli, such as lights and tones, acquire motivational properties by association with primary reinforcers (Robbins, 1976; Taylor and Robbins, 1984). This can be measured in a test of operant responding for a conditioned reinforcer (CR). In this procedure, rats learn to associate, through Pavlovian conditioning, an environmental stimulus (eg, light and a tone) with a reinforcer (eg, sucrose or drug). During a subsequent operant phase, rats learn to respond for the initially neutral stimulus that now functions as a CR. Incentive motivation is considered to be a fundamental aspect of motivation in general, and may have a crucial role in addiction and drugseeking behavior. For example, when cocaine users are presented with cocaine-associated cues, such as viewing someone purchase or prepare cocaine for self-administration, these stimuli can induce craving (Childress et al, 
1999). In adult rats, psychostimulants such as amphetamine and cocaine can enhance incentive motivation as measured by increased responding for CRs that were previously paired with natural reinforcers (Beninger and Ranaldi, 1992; Fletcher et al, 1998; Ranaldi and Beninger, 1993; Smith et al, 1997; Taylor and Robbins, 1984). This effect is mediated in part by increased activity of the mesocorticolimbic dopamine system upon which these psychostimulants act. One function of this pathway is to attribute incentive salience to stimuli, such that those stimuli become more 'attractive'. Augmented activity of this dopamine system can lead to attribution of maladaptively high incentive salience to the primary reinforcer (eg, drug) as well as to the stimuli associated with the reinforcer (Berridge and Robinson, 1998). This results in increased potential for the attribution of salience to environmental stimuli, such that these stimuli become increasingly 'wanted'. Alterations of incentive motivation have been suggested to increase drug-seeking and drug-taking, and therefore addictive behaviors, through enhancement of 'wanting' (Berridge and Robinson, 1998).

Incentive motivation may contribute to vulnerability to the effects of drugs of abuse during adolescence (Geier and Luna, 2009). Results of some studies suggest that adolescents do have increased incentive motivation for drugpaired cues. These studies using the conditioned place preference (CPP) procedure showed that, compared with adults adolescent rats prefer an environment that was previously paired with cocaine, amphetamine, or nicotine (Badanich et al, 2006; Laviola et al, 1999; Shram and Le, 2010; Torres et al, 2008; Zakharova et al, 2009a).

Our aim was to extend these findings by comparing adolescents and adults on responding for a CR previously paired with sucrose in adolescents and adults in a food- and water-deprived or non-deprived state. Having found an agerelated difference and in light of the findings of Olsen and Winder (2009), we further characterized this behavior by examining whether pairing the conditioned stimulus (CS) and sucrose during conditioning was critical for rats to respond for a CR. To examine whether motivation for sucrose, the primary reinforcer, might contribute to the agerelated difference in responding for a CR, we also examined responding for sucrose on a progressive ratio $(\mathrm{PR})$ schedule of reinforcement. Finally, we investigated the role of the dopamine and opioid receptors in responding for a CR in adolescent rats given their respective roles in 'wanting' and 'liking' as put forth by the incentive salience model (Berridge and Robinson, 1998).

\section{MATERIALS AND METHODS}

\section{Subjects}

Pregnant Sprague-Dawley dams (gestational day 13) and male adult rats (> postnatal day (PND) 70) were obtained from Charles River Farms (St Constant, QC, Canada). For each experiment, dams and pair-housed males were brought into the colony on the same day. On PND 4, litters were culled to five male and five female rats. However, in this and all other experiments, only male rats were used. Rats in the adolescent group ranged in ages from PND 25 (juvenile period) to PND 54 (early adulthood) throughout a given experiment. Because of the nature of the operant tasks used in these experiments it was difficult to restrict Pavlovian conditioning, $\mathrm{CR}$ testing, and locomotor activity to the strict adolescent period (PND 37-47). However, for the critical tests, rats were approximately the same age during Pavlovian conditioning (PND 25-38) and operant responding for a CR (PND 40-46) across experiments. The colony was maintained on a 12-h reverse light-dark cycle $(0900-$ 2100 hours) in a room maintained at $\sim 22^{\circ} \mathrm{C}$ and $\sim 50-60 \%$ humidity. The experimental procedures conformed to the guidelines of the Canadian Council on Animal Care (CCAC) and were approved by the Centre for Addiction and Mental Health Animal Care Committee.

\section{Weaning and Group Assignment}

On PND 21, each male adolescent rat was pair-housed with a rat from a different litter. A maximum of two rats per litter per group was used. All rats were given access to sucrose in the home cage for 3 days prior to training in all the experiments (adolescents PND 21-23 and adults > PND 70). For experiments 1, 2, and 4, separate cohorts of 12 adolescents and 12 adults per experiment were used. In Experiment-3, 24 adolescents and 12 adults were divided equally into two groups each (paired and unpaired). In Experiment-5, 36 rats were equally divided in to the following three groups: SCH 39166, eticlopride, and naltrexone.

\section{Apparatus}

Twelve operant conditioning boxes were used $(28 \mathrm{~cm}$ long $\times 21 \mathrm{~cm}$ wide $\times 21 \mathrm{~cm}$ high; Med. Associates, St Albans, VT). Two levers $4.5 \mathrm{~cm}$ wide and $7 \mathrm{~cm}$ above the floor with stimulus lights positioned directly above were located $6.5 \mathrm{~cm}$ on either side of a central, recessed magazine, with a solenoid valve positioned $3 \mathrm{~cm}$ from the floor of the chamber. Each chamber was illuminated by a house-light and housed in a sound-attenuating box equipped with a ventilating fan. Locomotor activity was tested with a custom-built locomotor activity monitor consisting of 16 clear polycarbonate cages $(25 \mathrm{~cm}$ wide $\times 20 \mathrm{~cm}$ high $\times$ $45 \mathrm{~cm}$ long) each equipped with an array of six infrared photocells spaced $7.5 \mathrm{~cm}$ apart and $2 \mathrm{~cm}$ above the floor along the lengths of the cage.

\section{Procedure}

Experiment-1a: responding for a $C R$ with food and water restriction. Adolescent (PND 24) and adult rats ( $>$ PND 70) were placed in the chambers for one 15-min session with $2 \mathrm{ml}$ of sucrose in the magazine receptacle; the response levers were retracted. The following day food and water were removed from the cages daily for $6 \mathrm{~h}(0800-1400$ hours) prior to behavioral testing until the end of the experiment. We found that rats exposed to this food restriction regimen gained weight across adolescence similarly to control rats (data not shown).

Pavlovian conditioning: Conditioning occurred in 14 daily 30 -min sessions. With the levers retracted, adolescent (PND 25-38) and adult rats (> PND 70) learned to associate 
the delivery of $0.1 \mathrm{ml}$ of $10 \%$ sucrose with the CS: two red stimulus lights were illuminated and the house-light was turned off for $5 \mathrm{~s}$ and during the last $0.5 \mathrm{~s}$ a tone was sounded $(2900 \mathrm{~Hz} ; 85 \mathrm{~dB})$. At the end of the tone the sucrose was delivered. The CS and reinforcer were presented on a random time 60-s (RT60) schedule (30 paired CS and sucrose presentations per session). To assess discriminated approach we measured nose pokes in the magazine during the 5-s CS periods (CSR) and during the 5-s periods immediately prior to CS periods (PCSR).

Operant responding for a CR: During this phase responding was never reinforced with sucrose. Adolescent (PND 39) and adult rats ( $>$ PND 70) were habituated to the levers in the chamber in one session. A response on the left lever delivered the CS (now the CR) according to a random ratio-2 (RR2) schedule (CR-active lever) and responses on the right lever had no programmed consequence (NCR-inactive lever). After $10 \mathrm{CR}$ lever presses, the session terminated. Next we measured responding for CR on a RR2 schedule in adolescent (PND 40-44) and adult rats ( $>$ PND 70 ) in three 40 -min sessions following intraperitoneal (IP) injections of saline, 0.25 , or $0.5 \mathrm{mg} / \mathrm{kg} \mathrm{D}$-amphetamine sulfate (US Pharmacopeia, Rockville, MD) immediately before the session. The order of the doses was counterbalanced and sessions occurred $48 \mathrm{~h}$ apart. We measured responses on the $\mathrm{CR}$ and NCR levers.

Experiment-1b: amphetamine-induced locomotion. Next, locomotor activity was assessed in a randomly selected subset of adolescent (PND 54) and adult rats ( $>$ PND 70; $n=8$ for both groups). First rats were exposed to the locomotor chambers for $2 \mathrm{~h}$. The following day, locomotion was measured for $2 \mathrm{~h}$ and then for another $1 \mathrm{~h}$ after a saline injection $(1 \mathrm{ml} / \mathrm{kg})$. Rats were then given an IP injection of $0.5 \mathrm{mg} / \mathrm{kg}$ amphetamine and activity was measured for another hour.

Experiment-2a: responding for a CR with no food and water restriction. The procedures for Experiment-2a were the same as for Experiment-1a except that rats were allowed free access to food and water throughout the entire experiment.

Experiment-2b: amphetamine-induced locomotion. Adolescent (PND 46-47) and adult ( $>$ PND 70) rats from Experiment-2a were used. The procedures for Experiment$2 \mathrm{~b}$ were the same as for Experiment- $1 \mathrm{~b}$.

Experiment-2c: extinction of responding for a CR. We examined whether responding on the lever that delivered the CR (CR lever) would extinguish across multiple daily 40-min sessions in adolescent (PND 48-54) and adult ( $>$ PND 70) rats. No sucrose was available during these sessions.

Experiment-3: role of pairing the CS and US on the acquisition of responding for a $C R$. The Pavlovian phase of the experiment was conducted as for Experiment-2a for adolescent and adult rats in the paired group. For rats in the unpaired group, both the CS and the unconditioned stimulus (US; sucrose) were presented 30 times each but never at the same time. Tests of operant responding for a $\mathrm{CR}$ were conducted as for Experiment-2a. We then examined whether responding on the CR lever extinguished after multiple sessions in adolescent (PND 48-56) and adult ( $>$ PND 70) rats as described for Experiment-2c.

Experiment-4a: responding for sucrose on a $P R$ schedule. Adolescent (PND 24-31) and adult ( $>$ PND 70) rats were trained to respond for $10 \%$ sucrose on a fixed ratio one (FR1) schedule of reinforcement. Each lever press delivered $0.1 \mathrm{ml}$ of sucrose and a white stimulus light was illuminated for $6 \mathrm{~s}$. During this $6 \mathrm{~s}$, lever presses were recorded but had no programmed consequences. For the first 3 days of training only, rats were food-restricted to facilitate learning to respond for sucrose. Adolescent rats were given approximately $8 \mathrm{~g}$ and adults were given approximately $16 \mathrm{~g}$ of Purina Rat chow per day. Starting the fourth day, all rats were fed ad lib. After responding stabilized, a PR schedule of reinforcement was introduced. The progression was derived from the equation ratio $=\left(5 \times \mathrm{e}^{(0.1 \times \text { infusion no. })}-5\right)$ yielding response ratios of $1,1,2,2,3,4,5,6,7,9,10,12,13$, $15,17,20$, etc. Thus the number of responses required for $0.1 \mathrm{ml}$ of sucrose increased with successive infusions. Sessions lasted until a period of $20 \mathrm{~min}$ without the delivery of a reinforcer, or were a maximum of $2 \mathrm{~h}$ in length. The number of reinforcers earned before this breaking point was recorded. On PND 38 for adolescents, food was removed from all rats in the afternoon after testing and the next day responding for sucrose on the PR schedule was examined. Afterwards, food was available ad lib for the remainder of the experiment. Responding was re-stabilized the following day.

Experiment-5a: the effect of SCH 39166, eticlopride, or naltrexone on responding for a CR. Only adolescent rats were used in this experiment. Pavlovian conditioning and lever habituation were conducted as described in Experimentla except that rats were allowed ad lib access to food and water. On PNDs 42, 44, and 46 responding on the CR and NCR lever under the influence of either SCH $39166(0,0.03$, or $0.06 \mathrm{mg} / \mathrm{kg}$, subcutaneously (SC); Tocris Bioscience, MO), eticlopride $(0,0.05$, or $0.1 \mathrm{mg} / \mathrm{kg}$, SC; Sigma, St Louis, MI), or naltrexone $(0,1$, or $2.0 \mathrm{mg} / \mathrm{kg}$, SC; Sigma, St Louis, MI) was measured in 40-min sessions. SCH 39166 and eticlopride were injected $15 \mathrm{~min}$ prior to and naltrexone was injected $30 \mathrm{~min}$ prior to the beginning of the session. The doses for all the groups were counterbalanced across the sessions.

Experiment-5b: the effect of SCH 39166, eticlopride, or naltrexone on responding for water in adolescent rats. Next, rats were trained to respond for a $0.01-\mathrm{ml}$ delivery of tap water on an RR2 schedule of reinforcement in 30-min sessions (PND 51-54). Prior to each session, rats were deprived of water for $15 \mathrm{~h}$. Once responding was stable (four sessions), rats from each respective group were injected with either saline or SCH $39166(0.6 \mathrm{mg} / \mathrm{kg})$, eticlopride $(0.05 \mathrm{mg} / \mathrm{kg})$, or naltrexone $(2 \mathrm{mg} / \mathrm{kg})$ over PND 55-57. The doses were counterbalanced across sessions and the pretreatment times were as described in Experiment-5a. The sessions were conducted $48 \mathrm{~h}$ apart. 


\section{Statistical Analyses}

Data were analyzed using the Statistica v7 software. For experiments 1 and 2, data from the Pavlovian phases of the $\mathrm{CR}$ experiments were analyzed by three-way analysis of variance (ANOVA) using session and discrimination (CSR/ PCSR) as within-subject factors and age as the betweensubject factor. Data from the operant phase of the $\mathrm{CR}$ experiments were analyzed by three-way ANOVA using drug (amphetamine or saline) and lever (CR, NCR) as within-subject factors and age as the between-subject factor. Responding on the CR and NCR lever during extinction was analyzed by three-way ANOVA (age $\times$ lever $\times$ session). For Experiment-3 we analyzed the conditioning data by four-way ANOVA (age $\times$ discrimination $\times$ session $\times$ contingency: CS and US paired or unpaired). We found a contingency $\times$ discrimination $\times$ session interaction and so to simplify the analyses for this experiment we analyzed the paired and unpaired groups separately. The effects of saline and amphetamine on locomotor activity were analyzed separately by two-way ANOVAs using age as the betweensubject factor and time as the within-subjects factor. For Experiment-4 the number of earned reinforcers was analyzed using age as the between-subject factor. The effects of overnight food deprivation on reinforcers earned were analyzed by repeated-measures analyses using age as the between-subject factor and session (session before food deprivation; session after food deprivation) as the withinsubject factor. For Experiment-6, responding during the Pavlovian phase was analyzed using group ( $\mathrm{SCH}$ 39166, eticlopride, or naltrexone) as the between-subject factor. For responding for a CR and water, these groups were analyzed separately by repeated-measures analyses. Bonferroni post hoc tests were used when appropriate.

\section{RESULTS}

\section{Experiment-1a: Responding for a CR with Food and Water Restriction}

Pavlovian conditioning. As shown in Figure 1a, rats responded in the magazine more during the CS periods than in the 5-s periods prior to the CS (main effect of discrimination; $\left.F_{(1,22)}=74.9, p<0.001\right)$, and this difference increased across sessions (session $\times$ discrimination; $\left.F_{(13,286)}=18.69, p<0.001\right)$. There was no main effect of age $\left(F_{(1,22)}=0.71, \mathrm{~ns}\right)$ and no significant interactions with age $(p>0.05)$.

Operant responding for a CR. The results of three-way ANOVA confirmed that rats responded more on the CR than the NCR lever (main effect; $F_{(1,22)}=26.64, p<0.001$ ) and amphetamine increased responding $\left(F_{(2,44)}=7.13\right.$, $p=0.002)$. Significant lever $\times$ age and lever $\times$ dose interactions $\left(F_{(2,44)}=6.51, p=0.003\right.$, and $F_{(1,22)}=8.55, p=0.008$, respectively) were also found. As shown in Figure 1, adolescent but not adult rats responded more on the $\mathrm{CR}$ lever than the NCR lever after saline and amphetamine injections $(p<0.05)$. Both doses of amphetamine increased $\mathrm{CR}$ responding compared with saline in adolescents $(p<0.05$; Figures $1 \mathrm{~b}$ and $c)$ but not in adult rats. Following saline injection, adolescent rats made $46.17 \pm 6.21$ responses and adult rats made $20.17 \pm 6.21$ responses on the CR lever. Using the Bonferroni test in the context of the overall ANOVA, this specific difference was not significant. However, to examine this apparent difference further we used a two-way ANOVA to analyze CR and NCR lever responding as a function of age under saline treatment. This showed a significant lever $\times$ age interaction $\left(F_{(1,22)}=10.84\right.$, $p=0.03)$. With this more restricted analysis of data, Bonferroni post hoc analyses showed that adolescents responded more than adults on the CR lever after a saline injection $(p=0.015)$.

\section{Experiment-1b: Amphetamine-Induced Locomotion}

Adolescent and adult rats previously deprived of food and water did not show significantly different levels of locomotor activity during the habituation phase $\left(F_{(1,14)}=\right.$ 0.912 , ns; data not shown) or after a saline injection $\left(F_{(1,14)}=0.4, \mathrm{~ns}\right)$. As shown in Figure 3a, amphetamine increased locomotor activity, although adolescents and adults did not significantly differ in their response $\left(F_{(1,14)}=\right.$ $1.94, \mathrm{~ns})$. The apparent reduction in amphetamine-induced locomotor activity in adolescent versus adult rats was not
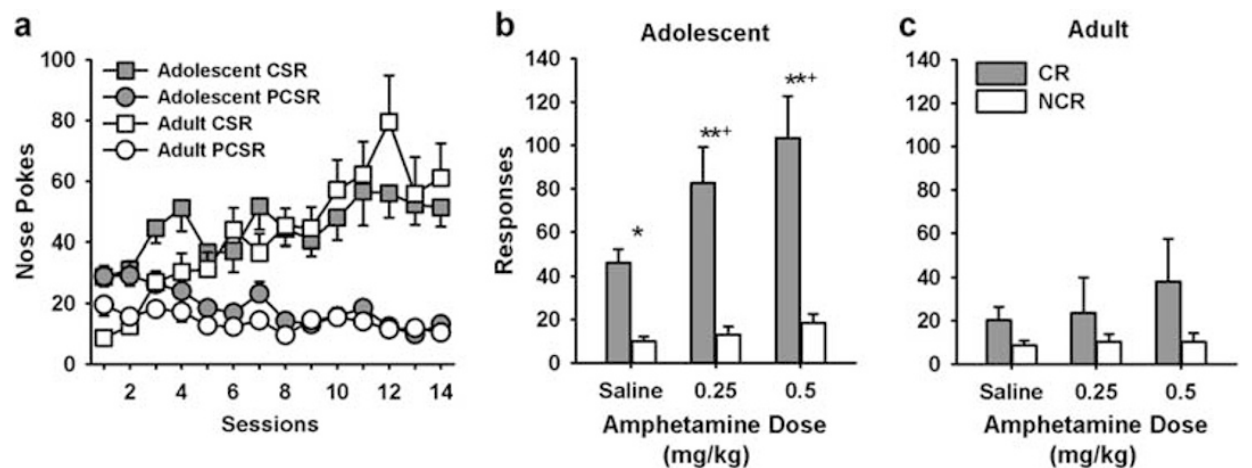

Figure I Responding for a CR in Food and Water Deprived Rats. (a) Approach behavior during conditioning was similar in adolescents and adults. The number of nose pokes during the CS periods (CS) as compared with the 5-s periods immediately prior to the conditioned stimulus (PCS) increased across sessions $(p<0.05)$. Adolescents (b) responded more on the CR than the NCR lever, whereas responding on the levers was not significantly different in adult rats (c). $* * * 0.01$; $*<<0.05$ : CR vs NCR responding. Amphetamine increased CR responding in adolescents rats only $(+p<0.05$, amphetamine $C R$ responding compared with baseline). Adolescents, $n=12$; adults, $n=12$. 
a

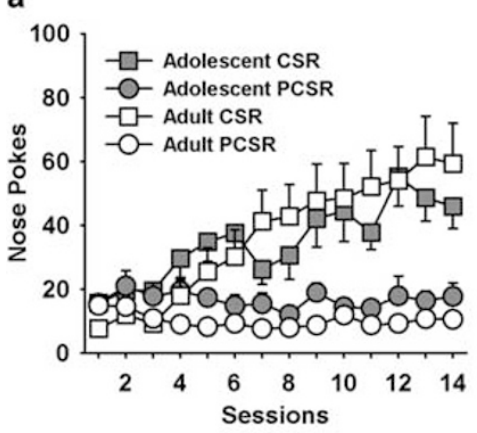

b

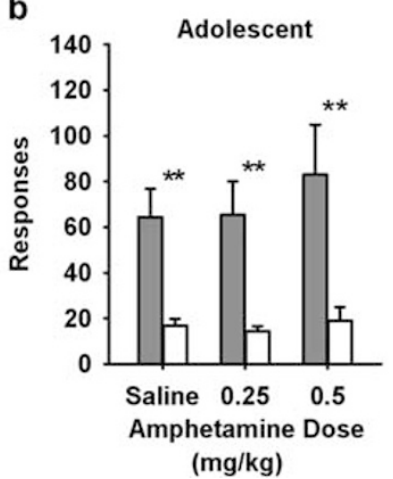

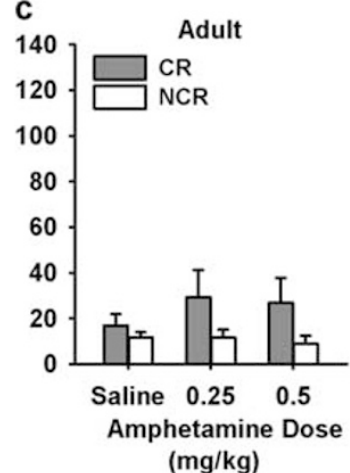

$(\mathrm{mg} / \mathrm{kg})$

Figure 2 Responding for a CR in Non-Food and Water-Deprived Rats. (a) Approach behavior during conditioning was similar in adolescents and adults. Adolescents (b) responded more on the CR than the NCR lever at baseline and with amphetamine, whereas adults (c) did not acquire responding for the

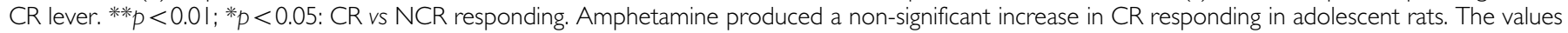
are the means \pm SEM. CSR, nose pokes during conditioned stimulus; PCSR, nose pokes in the 5-s period prior to the onset of the CS. CR, lever delivering light and tone; NCR, lever with no programmed consequence. Adolescents, $n=12$; adults, $n=12$.

significant $(p=0.19)$. No main effect of time and no time $\times$ age interaction was observed $\left(F_{(11,154)}=0.9\right.$, ns and $F_{(11,154)}=1.13$, ns respectively).

\section{Experiment-2a: Responding for a CR with no Restriction}

Pavlovian conditioning. As shown in Figure $2 \mathrm{a}$, rats responded in the magazine more during the CS periods than in the 5-s periods prior to the CS (main effect of discrimination; $\left.F_{(1,22)}=32.19,<0.001\right)$ and this difference increased across sessions (session $\times$ discrimination; $F_{(13 ., 86)}=18.61$, $p<0.001)$. There was no main effect of age $\left(F_{(1,22)}=0.25\right.$, ns) and no significant interactions with age $(p>0.05)$.

Operant responding for a CR. The results of the three-way ANOVA confirmed that rats responded more on the CR than the NCR lever (main effect; $F_{(1,22)}=31.00, p<0.001$ ) and adolescents responded more than adults $\left(F_{(1,22)}=7.31\right.$, $p=0.01)$. A lever $\times$ age interaction $\left(F_{(1,22)}=11.14, p=0.003\right)$ was also observed. As shown in Figure 2, adolescent but not adult rats responded more on the CR lever than the NCR lever after saline and amphetamine injections $(p<0.05)$. Following saline injection adolescent rats made $64.42 \pm 12.37$ responses and adult rats made $16.83 \pm 5.05$ responses on the CR lever. Using the Bonferroni test in the context of the overall ANOVA, this specific difference was not significant. However, to examine this apparent difference further we used a two-way ANOVA to analyze CR and NCR lever responding as a function of age under saline treatment. This showed a significant lever $\times$ age interaction $\left(F_{(1,22)}=15.203, p<0.001\right)$. With this more restricted analysis of data, Bonferroni post hoc analyses showed that adolescents responded more than adults on the CR lever after a saline injection $(p=0.03)$. As shown in Figure $2 \mathrm{~b}$, it appeared that $0.5 \mathrm{mg} / \mathrm{kg}$ amphetamine increased responding in adolescent rats $(p=0.143)$, but this was not significant with Bonferroni correction. In adult rats $\mathrm{CR}$ and NCR lever responding was not significantly different after saline or amphetamine injections.

\section{Experiment-2b: Amphetamine-Induced Locomotion}

Adolescent and adult rats not previously deprived of food and water did not show significantly different levels of locomotor activity during the habituation phase $\left(F_{(1,22)}=\right.$ 1.93, ns; data not shown) or after a saline injection $\left(F_{(1,22)}=0.008\right.$, ns; Figure 3b). After an amphetamine injection, locomotion increased but this increase was not significantly different between age groups $\left(F_{(1,22)}=3.0, \mathrm{~ns}\right)$. There was also no time $\times$ age interaction $\left(F_{(11,242)}=1.38, \mathrm{~ns}\right)$.

\section{Experiment-2c: Extinction}

As shown in Figure 4, overall responding decreased across repeated sessions (main effect; $F_{(6,132)}=8.25, p<0.001$ ), adolescents responded more than adults (main effect; $\left.F_{(1,22)}=8.54, p=0.008\right)$, and rats responded more on the CR than the NCR lever (main effect; $F_{(1,22)}=41.34$, $p<0.001)$. Further, there was an age $\times$ lever $\times$ session interaction $\left(F_{(6,132)}=3.65, p=0.002\right)$. Bonferroni post hoc tests showed that adolescent rats responded more on the CR than the NCR lever during the first four sessions only $(p<0.05)$. During the remaining sessions responding on both the CR and the NCR lever was low and stable. Adults did not respond significantly more on the CR than the NCR lever during any session $(p>0.05)$. By the last session there were no significant effects of age or lever.

\section{Experiment-3: Role of Pairing the CS and UCS in the Acquisition of Responding for a CR}

Pavlovian conditioning. A three-way ANOVA showed a significant main effect of contingency $\left(F_{(1,3)}=16.87\right.$, $p<0.001)$ and a contingency $\times$ discrimination $\times$ session interaction $\left(F_{(13,416)}=5.78, p<0.001\right)$ so the paired and unpaired groups were analyzed separately. Paired rats of both ages responded in the magazine more during the CS periods than in the 5-s periods prior to the CS, and this difference increased across sessions (main effect of discrimination; $F_{(1,16)}=25.65, p<0.001$; discrimination $\times$ session interaction: $\left.F_{(13,208)}=8.12, p<0.001\right)$. Adolescents also responded in the magazine more overall than adults (main effect of age; $F_{(1,16)}=5.38, p=0.034$ ), but there were no significant interactions with age and discrimination or session (ns; Figure 5a). Conversely, as shown in Figure 5b, in the unpaired group rats of both ages responded more during the 5-s periods prior to the CS than during the CS 
a Previously Food and Water Deprived

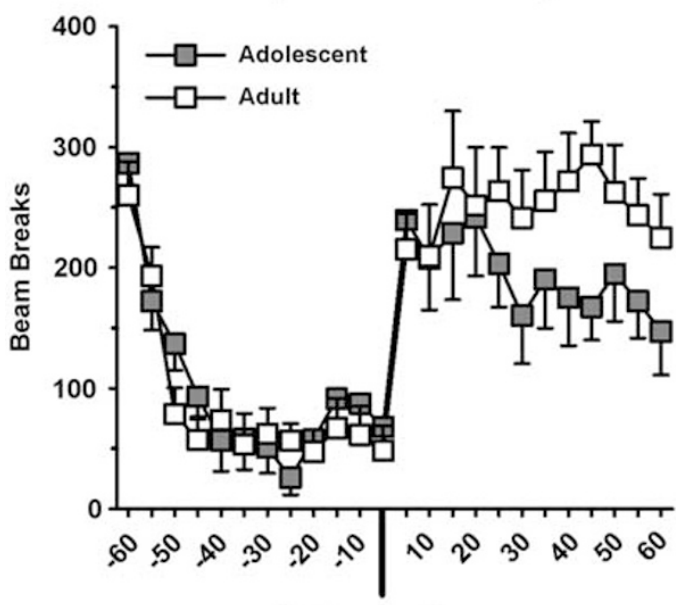

No Deprivation

b

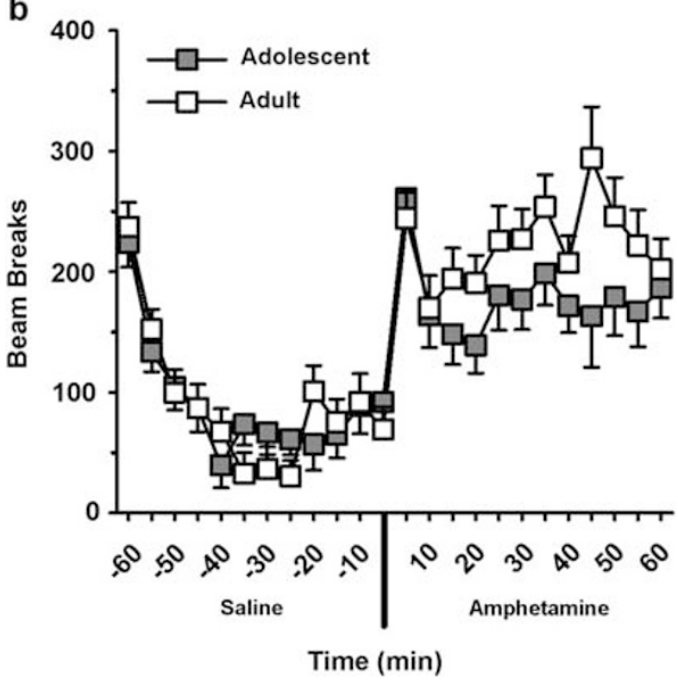

Figure 3 Amphetamine-Induced Locomotor Activity. For rats previously deprived of food and water (a; Experiment-I) and rats fed ad lib (b; Experiment-2), locomotor activity was not significantly different between adolescent and adult rats after a saline or amphetamine injection. Amphetamine non-significantly reduced amphetamine-induced locomotion. The values are the means \pm SEM. AMPH, amphetamine. In panel a: adolescents, $n=8$; adults, $n=8$. In panel b: adolescents, $n=12$; adults, $n=12$.

periods, although responding was low and stable during both periods (main effect of discrimination; $F_{(1,16)}=45.94$, $p<0.001)$. There was no discrimination $\times$ session interaction $\left(F_{(13,208)}=0.78, \mathrm{~ns}\right)$.

Operant responding for a CR. We analyzed the effects of a paired or unpaired CS-US on operant responding for the CR. As shown in Figures $6 a$ and $b$, for rats in the unpaired groups, rats responded more on the CR than the NCR lever, although generally responding was low (main effect of lever; $\left.F_{(1,16)}=8.88, p=0.008\right)$ and there was a lever $\times$ age interaction $\left(F_{(1,16)}=7.29, p=0.016\right)$. Although it appeared that adolescents in the unpaired group responded more on the CR than the NCR lever, this was not significant $(p=0.29)$. As shown in Figures $6 c$ and d, for rats in the paired group, adolescents responded more than adults after saline and amphetamine injections (main effect of age; $F_{(1,16)}=4.2$,

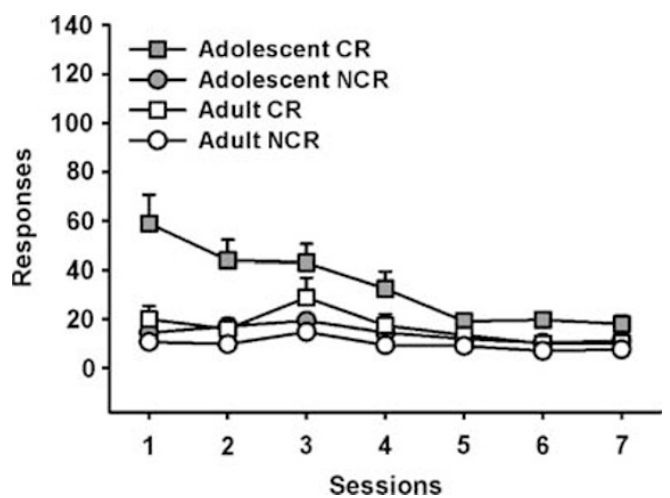

Figure 4 Extinction of Responding for a CR. Adolescent rats responded more on the $C R$ than the NCR lever during the first four sessions $(p<0.05)$, although $C R$ responding decreased across sessions until responding was not significantly different between levers. Responding on both the CR and the NCR lever was low and stable in adult rats. CR, lever delivering light and tone; NCR, lever with no programmed consequence. Adolescents, $n=12$; adults, $n=12$.

$p=0.05)$ and rats responded more on the CR than the NCR lever (main effect of lever; $F_{(1,16)}=9.88, p=0.006$ ), with adolescents responding more on the $\mathrm{CR}$ lever than adults $\left(\right.$ age $\times$ lever interaction; $\left.F_{(2,32)}=3.54, p=0.05\right)$.

\section{Experiment-3b: Extinction of Responding for a CR}

In the paired group, overall responding decreased across sessions $\left(F_{(15,240)}=4.14, p<0.001\right)$, although adolescents responded more than adults $\left(F_{(1,16)}=10.87, p<0.001\right)$, and rats responded more on the $\mathrm{CR}$ than the NCR lever $\left(F_{(1,16)}=27.07, p<0.001\right)$. There was also a marginal but non-significant age $\times$ session $\times$ lever interaction $\left(F_{(15,240)}=\right.$ $1.62, p=0.06)$. Bonferroni post hoc tests showed that in adolescent rats responding on the CR lever was significantly greater than on the NCR lever from sessions $1-9(p<0.05)$ but not during the remaining sessions. In adult rats responding on the CR and NCR lever was not significantly different during any session ( $p>0.1$; see Table 1 for values). In the unpaired group, responding decreased across sessions $\left(F_{(1,16)}=10.87, p<0.001\right)$ and rats responded more on the CR than the NCR lever $\left(F_{(1,16)}=10.87, p<0.001\right)$. However, responding on the $\mathrm{CR}$ and NCR lever was low across all sessions ( $<15$ responses). There were no significant interactions (ns).

\section{Experiment-4: Responding for Sucrose on a PR Schedule}

As shown in Figure 7a, adolescents and adult rats readily acquired responding for sucrose on a PR schedule. Adults earned more reinforcers than adolescents (main effect of age; $\left.F_{(1,22)}=14.9, p=0.001\right)$. There was no main effect of session and no session $\times$ age interaction for the reinforcers earned. As shown in Figure 7b, adolescents consumed more sucrose as a function of body weight $(\mathrm{g} / \mathrm{kg})\left(F_{(1,22)}=\right.$ $103.85, p<0.001)$; however, the amount of sucrose consumed decreased over time for adolescent rats, whereas adult sucrose consumption remained stable (age $\times$ session interaction: $\left.F_{(6,132)}=2.45, p=0.028\right)$.

After responding was stable under the PR schedule, we examined the effects of overnight food deprivation on 

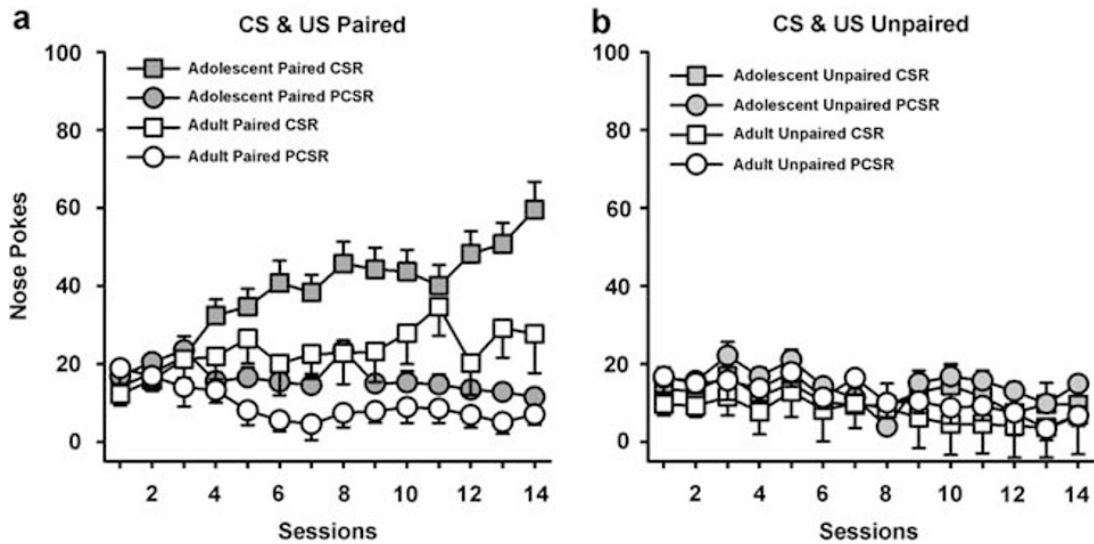

Figure 5 Approach Behavior (Paired vs Unpaired CS and Sucrose Experiment). As shown in panel a, both adolescent and adult rats that had paired delivery of the CS and sucrose showed discriminated approach toward the magazine during the CS compared with during the 5-s period prior to the CS. As shown in panel b, both adolescent and adult rats that received both CS and sucrose delivery but never together did not show discriminated approach to the magazine during the CS. The values are the means \pm SEM. CSR, nose pokes during conditioned stimulus; PCSR, nose pokes in the 5-s period prior to the onset of the CS. Paired adolescents, $n=12$; unpaired adolescents, $n=12$; paired adults, $n=6$; unpaired adults, $n=6$.
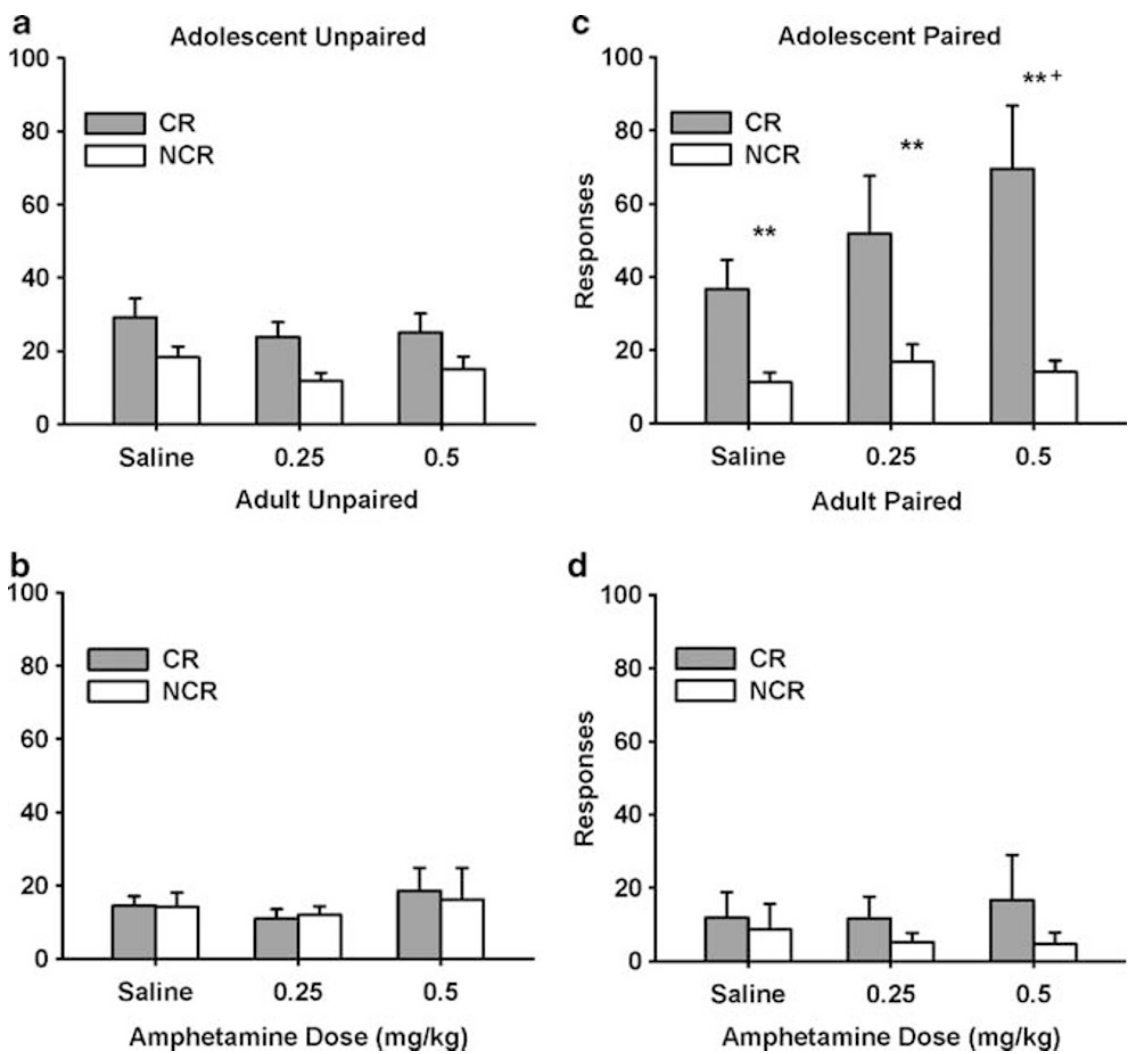

Figure 6 Responding for a CR (Paired vs Unpaired CS and Sucrose Experiment). All adult rats and adolescent rats that did not have the CS and sucrose delivery paired during Pavlovian conditioning had significantly greater responding on the CR than the NCR lever, and amphetamine did not increase responding $(\mathrm{a}, \mathrm{b})$. Adolescent rats that had the CS and sucrose delivery paired during Pavlovian conditioning responded more on the CR compared with the NCR lever at baseline and in response to amphetamine (c, $d: * * * 0.0 \mathrm{l}$ : CR vs NCR responding). Amphetamine $(0.5 \mathrm{mg} / \mathrm{kg})$ increased responding on the $C R$ lever compared with baseline $(+p<0.05)$. The values are the means $\pm S E M$. $C R$, lever delivering light and tone; NCR, lever with no programmed consequence. Paired adolescents, $n=12$; unpaired adolescents, $n=12$; paired adults, $n=6$; unpaired adults, $n=6$.

responding for sucrose. Food deprivation increased the number of reinforcers earned (main effect of session; $\left.F_{(1,22)}=6.63, p<0.001\right)$ and generally adults earned more reinforcers than adolescents (main effect of age; $F_{(1,22)}=$ $14.9, p=0.02)$. There was a significant age $\times$ session interaction $\left(F_{(1,22)}=6.32, p=0.02\right)$. As shown in Figure $7 \mathrm{c}$, compared with the previous session adolescents showed increased responding after food deprivation whereas adults did not. Food deprivation also increased the $\mathrm{g} / \mathrm{kg}$ of sucrose consumed (main effect of session; $F_{(1,22)}=60.39, p<0.001$ ), and compared with adults adolescents consumed more $\mathrm{g} / \mathrm{kg}$ of sucrose (main effect of age; $F_{(1,22)}=51.44, p<0.001$ ). 
There was also an age $\times$ session interaction $\left(F_{(1,22)}=27.33\right.$, $p<0.001)$. Bonferroni post hoc tests showed that food deprivation increased the $\mathrm{g} / \mathrm{kg}$ of sucrose consumed in adolescents but not adults $(p<0.05$; Figure $7 d)$.

Experiment-5a: The Effect of SCH 39166, Eticlopride, and Naltrexone on Responding for a CR in Adolescent rats

Pavlovian conditioning. Rats responded more in the magazine during the CS periods than in the 5-s periods prior to the CS (main effect of discrimination; $F_{(13,429)}=$ 29.77, $p<0.001$ ), and this difference increased across sessions (session $\times$ discrimination; $F_{(13,429)}=57.35, p<0.001$ ).

Table I Extinction of Responding for a CR (Paired vs Unpaired CS and Sucrose Experiment)

\begin{tabular}{lcccc}
\hline Group & First session & First session & Last session & Last session \\
& CR & NCR & CR & NCR \\
\hline Adolescent paired & $37( \pm 7.26)^{* * *}$ & $12( \pm 2.77)$ & $16.83( \pm 2.01)$ & $11.5( \pm 2.13)$ \\
Adolescent unpaired & $14.75( \pm 2.22)$ & $11( \pm 2.05)$ & $7.83( \pm 1.36)$ & $9.75( \pm 3.68)$ \\
Adult paired & $13.5( \pm 8.10)$ & $4.83( \pm 3.11)$ & $7.89( \pm 2.46)$ & $8.67( \pm 4.39)$ \\
Adult unpaired & $8.5( \pm 1.56)$ & $7.83( \pm 2.84)$ & $4.33( \pm 0.96)$ & $4.6( \pm 0.78)$
\end{tabular}

During the first sessions, after responding for a conditioned reward was observed, only adolescent paired rats responded more on the CR than the NCR lever (** < 0.003: CR vs NCR lever). By the final session, CR and NCR responding was not significantly different in all groups. $C R$, lever delivering light and tone; NCR, lever with no programmed consequence. Paired adolescents, $n=12$; unpaired adolescents, $n=12$; paired adults, $n=6$; unpaired adults $n=6$.
The three drug groups were not significantly different (main effect; $F_{(1,33)}=0.225$, ns) and there were no significant interactions with age ( $p>0.05$; data not shown).

Operant responding for a $C R$. As seen in Figure 8a, for the SCH 39166 group rats responded more on the CR than the NCR lever (main effect; $F_{(1,11)}=21.95, p<0.001$ ) and SCH 39166 reduced responding $\left(F_{(2,22)}=7.04, p=0.0041\right)$. There was also a lever $\times$ dose interaction $\left(F_{(2,22)}=4.41, p=0.02\right)$. Post hoc analyses showed that, compared with the saline condition $\mathrm{CR}$ responding was only decreased after the highest dose $(0.06 \mathrm{mg} / \mathrm{kg})$ of SCH $39166(p<0.05)$. Responding on the NCR lever was not significantly reduced by either dose of SCH 39166 (ns).

For the eticlopride group, rats responded more on the $\mathrm{CR}$ than the NCR lever (main effect; $F_{(1,11)}=16.38, p<0.001$ ) and eticlopride reduced responding $\left(F_{(2,22)}=12.36\right.$, $p=0.001)$. There was also a lever $\times$ dose interaction $\left(F_{(2,22)}=6.18, p=0.007\right)$. Post hoc analyses showed that, compared with the saline condition CR responding was decreased by both doses of eticlopride ( $p<0.01$; Figure $8 \mathrm{~b})$. Responding on the NCR lever was not significantly reduced by either dose of eticlopride (ns).

As shown in Figure 8c, rats in the naltrexone group responded more on the CR than the NCR lever (main effect; $\left.F_{(1,11)}=23.04, p<0.001\right)$ and naltrexone reduced responding $\left(F_{(2,22)}=4.67, p=0.02\right)$. There was no lever $\times$ dose interaction $\left(F_{(2,22)}=2.93\right.$, ns). Post hoc analyses showed that, compared with the saline condition $\mathrm{CR}$ responding was decreased by the highest dose of naltrexone $(p<0.01)$. a

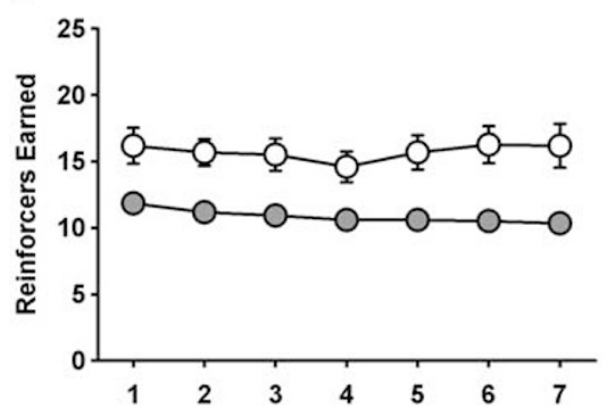

b

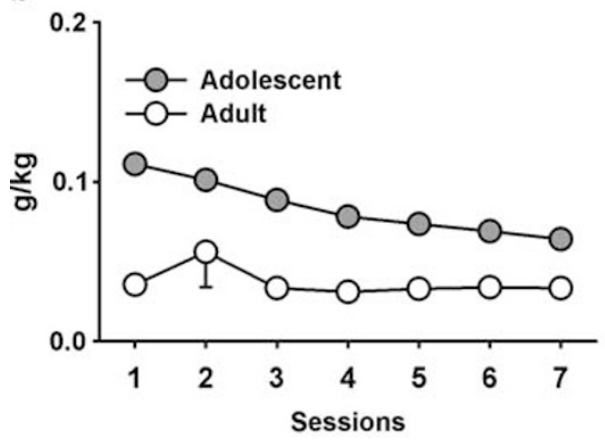

\section{C}

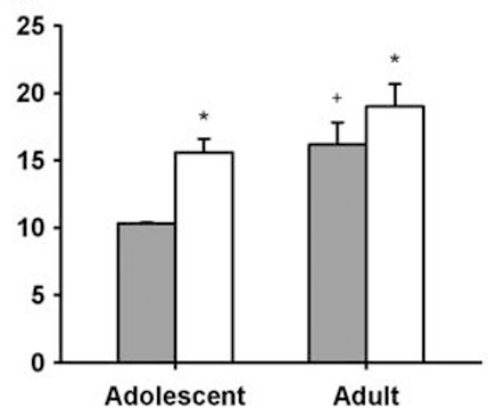

d

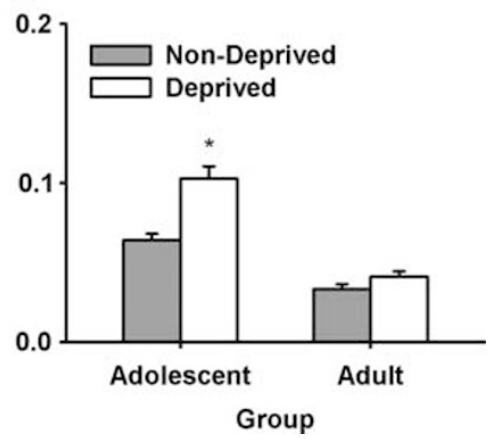

Figure 7 Responding for Sucrose on a PR Schedule. (a) Adults earned more reinforcers than adolescent rats at baseline. Adolescents consumed more g/kg of sucrose than adults, although this decreased across sessions (b). (c) Food deprivation increased the number of reinforcers earned in both adolescent and adult rats, although the increase was greater in adolescent rats ( $p<0.05$ : non-deprived vs deprived; $+p<0.05$ : adults vs adolescents). Food deprivation only increased the $\mathrm{g} / \mathrm{kg}$ of sucrose consumed in adolescent rats ( $\mathrm{d}$ : $*<<0.05$ : non-deprived vs deprived). The values are the means $\pm S E M$. Adolescents, $n=12$; adults, $n=12$. 

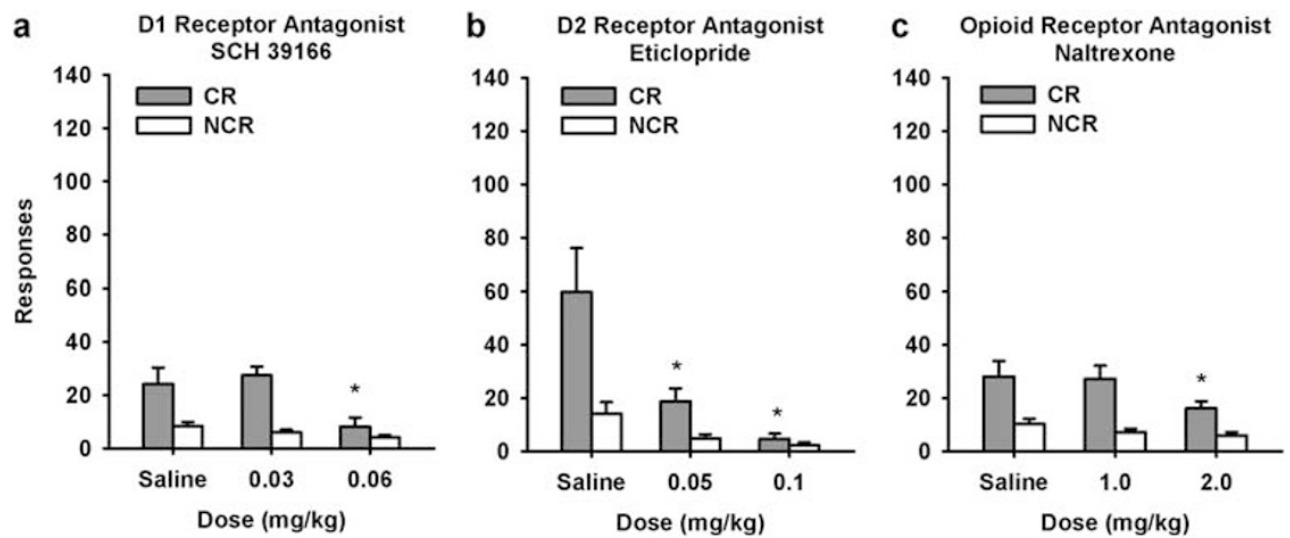

Figure 8 The Effect of SCH 39 I 66, Eticlopride, and Naltrexone on Responding for a CR in Adolescent Rats. SCH 39 I 66 (0.06 mg/kg; D, dopamine receptor), eticlopride (0.05 and $0.1 \mathrm{mg} / \mathrm{kg} ; \mathrm{D}_{2}$ dopamine receptor antagonist), and naltrexone (2.0 mg/kg; opioid receptor antagonist) decreased CR lever responding compared with saline as shown in panels $a, b$, and c, respectively. (** $<0.01$ : CR saline vs CR antagonist) The values are the means \pm SEM. CR, lever delivering light and tone; NCR, lever with no programmed consequence. SCH 39|66, $n=12$; eticlopride, $n=12$; naltrexone $n=12$.

Responding on the NCR lever was not significantly reduced by either dose of naltrexone (ns).

To examine whether a higher dose of naltrexone would reduce responding for the CR even further, we conducted an additional two test sessions using vehicle and $3 \mathrm{mg} / \mathrm{kg}$ naltrexone. We found that responding for the $\mathrm{CR}$ at $3 \mathrm{mg} / \mathrm{kg}$ was similar to responding with $2 \mathrm{mg} / \mathrm{kg}$ naltrexone $(2 \mathrm{mg} / \mathrm{kg}$ CR responses: $16.08 \pm 2.74$, NCR responses: $5.92 \pm 1.3 ; 3 \mathrm{mg} / \mathrm{kg}$ CR responses: $18.5 \pm 2.99$; NCR responses: $7.92 \pm 2.01$; data not shown).

\section{Experiment-5b: the Effect of SCH 39166, Eticlopride, and Naltrexone on Responding for Water in Adolescent Rats}

All rats readily acquired responding for water on an RR2 schedule of reinforcement (data not shown). The average responses for each group during the four acquisition sessions were as follows: SCH 39166: $398.33 \pm 56.56$; eticlopride: $372.62 \pm 44.5$; and naltrexone: $399.71 \pm 34.3$. During testing, SCH 39166 and naltrexone significantly reduced responding for water compared with saline (main effect of dose; $F_{(1,11)}=56.73, p<0.001$, and $F_{(1,11)}=25.56, p<0.001$, respectively). The highest dose of eticlopride $(0.1 \mathrm{mg} / \mathrm{kg})$ almost completely abolished responding (data not shown; average of $8.2 \pm 5.8$ responses; $n=6$ ). We then tested the lower dose of eticlopride $(0.05 \mathrm{mg} / \mathrm{kg})$ in the remaining six rats. Eticlopride also significantly reduced responding for water compared with saline (main effect; $F_{(1,5)}=15.64$, $p=0.008)$. See Table 2 for values.

\section{DISCUSSION}

Adolescent but not adult rats acquired responding for a CR previously paired with sucrose, indicating enhanced incentive motivation for reward-paired cues in adolescence. This effect was unlikely because of enhanced motivation for the primary reinforcer in adolescence because adolescent rats did not respond more than adults for the $10 \%$ sucrose. Further, adolescent rats only responded for a CR when it had been previously paired with sucrose, suggesting that the
Table 2 The Effect of SCH 39166, Eticlopride, and Naltrexone on Responding for Water

\begin{tabular}{lrr}
\hline Group & Saline responses & Antagonist responses \\
\hline SCH 39166 & $486.42( \pm 73.14)$ & $91( \pm 36.92)^{* *}$ \\
Eticlopride & $402.5( \pm 74.62)$ & $72.83( \pm 26.09)^{* *}$ \\
Naltrexone & $495.17( \pm 51.32)$ & $305.58( \pm 33.07)^{* * *}$ \\
\hline
\end{tabular}

$\mathrm{SCH} 39166$, eticlopride, and naltrexone all significantly reduced responding for water on an RR2 schedule of reinforcement compared with saline $(* * 2<0.01)$. The values are the means \pm SEM. SCH 39|66, $n=12$; eticlopride, $n=6$; naltrexone, $n=12$.

enhanced responding on the CR lever was not driven by an increased motivation for the light and tone alone (eg, Olsen and Winder, 2009). Finally, responding for a CR during adolescence appeared to be mediated in part by both the dopamine and the opioid systems.

In the present study, the acquisition of responding for a $\mathrm{CR}$ in only adolescent rats was a robust and reliable effect. This behavioral difference was observed in three separate experiments and under various conditions. Acquisition of responding for a $\mathrm{CR}$ in adolescent but not adult rats was observed regardless of the level of food deprivation. Thus, responding for a CR in adolescent rats was not dependent on hunger and was more likely related to the acquired incentive value of the CS. Responding for the CR also extinguished following multiple exposures in adolescent rats in two separate experiments. This likely indicates that rats had learned an association between the CS and US, and therefore when sucrose was no longer delivered with the CS after multiple sessions, responding for that stimulus was reduced. Further evidence that the acquisition of responding for a CR reflected a learned association between the CS and the reinforcer was that the light and tone stimulus only supported operant responding if it had been previously paired with sucrose. Thus rats not only learned that the light and tone predicted the delivery of sucrose, but also that the incentive value of the CS, and not the light and tone itself, 
supported responding for the CR. This distinction is important because Olsen and Winder (2009) showed that adult rats respond for a flashing light and this responding was resistant to extinction. In the present experiment, when the CS was not paired with sucrose during conditioning, rats responded less on the $\mathrm{CR}$ lever and this responding remained low and stable throughout the extinction sessions. Together, our findings that responding for a CR was (1) enhanced in adolescent rats compared with adults in multiple experiments and regardless of their level of food deprivation; (2) extinguished with repeated exposure to the CR without the primary reinforcer; and (3) dependent on the pairing of the CS and sucrose, show that adolescents have enhanced incentive motivation for cues previously paired with a natural reinforcer.

Adults did not significantly respond for a CR in any of the present experiments. This lack of effect may be because we used only mild or no food deprivation. In previous studies using more severe deprivation regimens, adult rats responded for a CR (Burton et al, 2009; Fletcher and Korth, 1999; Taylor and Robbins, 1984). We found in a pilot work that these more severe food deprivation regimens do not permit adolescents to gain weight normally. Given that this is a potential confound, we chose a less severe regimen that was sufficient to motivate rats to learn a discriminated approach behavior and still permitted adolescent rats to gain weight comparably to non-restricted controls (data not shown). Although in the present study adult rats did not acquire responding for a $\mathrm{CR}$, the same rats during the Pavlovian conditioning phase approached the site of reinforcer delivery during the presentations of the CS similarly to adolescent rats. This implies that adults learned that the CS predicted reinforcer delivery even though subsequently this CS did not support responding (ie, did not acquire incentive salience) in the absence of delivery of the primary reinforcer.

Free-fed adolescent rats did not respond more than adults for $10 \%$ sucrose on a PR schedule of reinforcement. Adolescents only consumed on average $1 \mathrm{ml}$ of sucrose during the 1-h sessions; thus reduced responding in the adolescents is unlikely related to satiation. Food deprivation increased the number of earned sucrose reinforcers to a greater extent in adolescents compared with adults, which may be interpreted as increased motivation for sucrose under those conditions. However, adolescent rats responded more for a CR regardless of their level of food deprivation in experiments 1 and 2. Also, mildly deprived adolescent rats ( $\sim 40$ responses) responded less on the CR lever than non-deprived rats ( $\sim 60$ responses), which implies that level of deprivation was not directly related to the amount of responding on the CR lever. Together, these data imply that enhanced responding for the $C R$ in adolescent compared with adult rats was unlikely driven by enhanced motivation for the sucrose reinforcer itself. We also found that, compared with adults adolescent rats consumed more sucrose as a function of their body weight (g/kg), although this difference decreased with age. Although in adolescents the amount of sucrose consumed as a function of body weight decreased across sessions, the number of reinforcers earned did not vary as a function of body weight. Thus although compared with adults adolescent rats consumed more sucrose as a function of body weight, they were not more willing than adults to work for sucrose. Further evidence that adolescents were seemingly not more motivated than adults for sucrose in the present experiments is that discriminated approach behavior during the Pavlovian conditioning phase was similar between age groups in most of the experiments. Adolescents also showed enhanced responding for a CR regardless of their state of satiety. Some previous studies suggest that, compared with adults adolescents may find sweet liquids more rewarding. Adolescent rats show increased hedonic responses to $10 \%$ sucrose and consumed more $1 \%$ sucrose as a function of body weight than adults (Wilmouth and Spear, 2009). In self-administration studies using the PR schedule of reinforcement, compared with adults adolescents worked harder for condensed milk (Friemel et al, 2010) but not for saccharin (Shram et al, 2007). These discrepant findings, combined with our data, indicate that adolescents are not consistently more motivated than adults by sweet-tasting rewards.

Our finding that adolescents show enhanced incentive motivation compared with adults is consistent with previous studies. Adolescent male rats showed enhanced cocaine and amphetamine CPP compared with adult male rats (Badanich et al, 2006; Laviola et al, 1999; Zakharova et al, 2009a; Zakharova et al, 2009b), although this is not consistent across all studies (eg, Aberg et al, 2007; Campbell et al, 2000; Mathews and McCormick, 2007). Adolescents also show enhanced CPP compared with adults for nicotine (Shram et al, 2010; Torres et al, 2008), methamphetamine (Zakharova et al, 2009a), and natural reinforcers, such as a novel object (Douglas et al, 2003). Compared with adults adolescent rats also show enhanced c-fos protein expression in the nucleus accumbens core and dorsal striatum in response to an odor cue previously paired with a sweet reward (Friemel et al, 2010). These findings indicate that adolescents show enhanced motivation and neuronal activation for reward-paired cues - our data now show that adolescent rats will work more than adults for the same type of cues.

Amphetamine, a dopamine releaser, enhanced responding for a CR in adolescent more than in adult rats. This behavioral difference is unlikely because of differential amphetamine-induced locomotor activity. The same adolescent rats that showed enhanced amphetamine-induced responding for a $\mathrm{CR}$ tended to be hypo-responsive to the locomotor-stimulating effects of amphetamine compared with adults, which supports previous findings (Bolanos et al, 1998; Lanier and Isaacson, 1977; Laviola et al, 1999). A more likely interpretation for the differential effect of amphetamine between adolescents and adults is the differential drug-free responding for a CR. Amphetamine is known to potentiate a pre-existing response for a CR (Beninger and Ranaldi, 1992; Fletcher et al, 1998; Ranaldi and Beninger, 1993; Smith et al, 1997; Taylor and Robbins, 1984). As adults did not respond for a CR after a saline injection in any experiment, amphetamine likely only selectively increased responding for a CR in adolescent rats compared with adults because this response was only observed in adolescent rats.

Complementary to our results that amphetamine enhanced responding for a $C R$ in adolescents, the $D_{1}$ dopamine receptor antagonist $\mathrm{SCH} 39166$ and the $\mathrm{D}_{2}$ dopamine 
receptor antagonist eticlopride significantly reduced responding for a CR. These findings are consistent with several previous experiments in adult rats showing the role of dopamine receptors in responding for a CR (Beninger and Ranaldi, 1992; Fletcher and Higgins, 1997; Fletcher et al, 1998; Ranaldi and Beninger, 1993; Robbins, 1976; Robbins et al, 1983; Smith et al, 1997; Sutton and Beninger, 1999; Taylor and Robbins, 1984). Given that dopamine receptor antagonists can also disrupt motor function, the potential role of the motor-depressing effects of these drugs on responding for a CR must be considered. Both SCH 39166 and eticlopride reduced responding for water on an RR2 schedule. However, doses of eticlopride $(0.05 \mathrm{mg} / \mathrm{kg})$ and SCH $39166(0.06 \mathrm{mg} / \mathrm{kg})$ that significantly reduced responding for a CR also permitted rats to physically make more responses than the rats had previously made for a CR after a saline injection ( $>50$ responses). Together, these findings suggest a role for dopamine in incentive motivation, and motivation in general, as argued by others (Berridge, 2007; Berridge and Robinson, 1998; Everitt et al, 1999), although the potential contribution of reduced motor effects cannot be completely ruled out.

The opioid system also has a role in mediating reward (Barbano and Cador, 2007; Berridge, 1996, 2009; Petrovic et al, 2008; Schneider et al, 2010; Smith and Berridge, 2007). We showed that naltrexone, a non-selective opioid receptor antagonist, also reduced responding for a CR in adolescent rats. This effect is unlikely to be the result of motor impairments because rats made on average over 300 responses for water after a naltrexone injection. Our data are consistent with a previous study reporting that morphine increased responding for a CR (Robbins et al, 1983). Together, these findings suggest a role of the opioid system in responding for a CR and incentive motivation.

Responding for a CR in adult rats is known to be mediated in part by the limbic-striatal circuitry and the mesocorticolimbic dopamine pathway (Everitt et al, 1999). The acquisition of a response for a $\mathrm{CR}$ is dependent on the basolateral amygdala (BLA) and the nucleus accumbens core, which receives many afferent projections from the BLA (Burns et al, 1993; Everitt et al, 1999; Taylor and Robbins, 1984). The psychostimulant potentiation of responding for a $\mathrm{CR}$ is mediated by dopamine in the nucleus accumbens shell (Taylor and Robbins, 1984). Both the core and the shell regions of the nucleus accumbens are richly innervated by dopaminergic projections from the ventral tegmental area (VTA). Inactivation of the VTA blocks responding for a CR (Murschall and Hauber, 2006). Although it is part of the mesocorticolimbic pathway, the prefrontal cortex (PFC) is not believed to be critical for acquiring responding for a CR in adults (Burns et al, 1993; Everitt et al, 1999; Pears et al, 2003). Therefore in adult rats, connections between the nucleus accumbens and the BLA combined with dopaminergic innervation from the VTA mediate responding for a CR.

This limbic-striatal circuit is still developing during adolescence. In particular, connections between the striatum, the amygdala, and the PFC undergo many changes throughout adolescence, and thus the PFC may have a role in the enhanced responding for a CR observed in adolescent rats compared with adults. Reciprocal projections from the BLA to the PFC continue to develop during adolescence
(Cressman et al, 2010; Cunningham et al, 2002, 2008). PFC dopamine fiber density and dopaminergic input from the striatum increase and peak during adolescence (Kalsbeek et al, 1988; Lewis, 1997). In the PFC both $\mathrm{D}_{1}$ and $\mathrm{D}_{2}$ dopamine receptor densities remain elevated until early adulthood (Andersen et al, 2000; Teicher et al, 1995), whereas in the ventral striatum there is greater $D_{1}$ compared with $\mathrm{D}_{2}$ dopamine receptor binding and receptor density during periadolescence. Increased $D_{1}$ dopamine receptor expression in the nucleus accumbens and PFC may be related to enhanced incentive motivation during adolescence. This is supported by the report that increased $D_{1}$ dopamine receptor expression in the PFC-accumbal pathway mediates increased cocaine CPP in adolescent rats (Brenhouse et al, 2008). These data suggest, as discussed in Ernst's triadic model (Ernst et al, 2006), that during adolescence an immature PFC supervisory system contributes to an overactive striatal reward system. The dynamic state of the mesocorticolimbic dopamine system during adolescence may mediate in part the enhanced responding for $\mathrm{CR}$ and incentive motivation.

Relatively less is known about the development of the opioid system during adolescence. Some report that opioid receptors appear to peak during the second postnatal week and decline until adulthood (Winzer-Serhan et al, 2003), whereas others reported that $\mu$ opioid receptors are relatively stable across the adolescent period (Ellgren et al, 2008; Talbot et al, 2005). Therefore, although previous studies imply that the immature state of the mesocorticolimbic system may be involved in the enhanced incentive motivation during adolescence, the role of the opioid system is less clear.

In conclusion, this study indicates that adolescent rats show enhanced incentive motivation for sucrose-paired cues compared with adults. This might contribute to enhanced vulnerability to the effects of drugs of abuse through increasing the probability of incentive salience attribution to stimuli paired with reinforcers, and in turn may increase 'wanting' and cravings more easily than in adults. Although these findings may suggest that adolescents are more prone to develop a 'wanting' of reinforcers and thus may be more vulnerable to some of the effects of drugs of abuse, the interpretations from this study are limited to natural reinforcers. We are currently investigating whether these findings also extend to drug-paired cues. Altered incentive motivation during adolescence may in part confer a vulnerability to the effects of drugs of abuse during this period and in turn the development of substance abuse disorders.

\section{ACKNOWLEDGEMENTS}

We thank Drs Anh Le, Alison Fleming, and Suzanne Erb for guidance and advice on the work, and Zoe Rizos, Romina Coppa-Hopman, and Judy Sinyard for technical assistance. This work was supported by a CIHR Doctoral Award to CLB and a Discovery Grant from NSERC to PJF.

\section{DISCLOSURE}

The authors have no conflicts of interest. 


\section{REFERENCES}

Aberg M, Wade D, Wall E, Izenwasser S (2007). Effect of MDMA (ecstasy) on activity and cocaine conditioned place preference in adult and adolescent rats. Neurotoxicol Teratol 29: 37-46.

Andersen SL, Thompson AT, Rutstein M, Hostetter JC, Teicher MH (2000). Dopamine receptor pruning in prefrontal cortex during the periadolescent period in rats. Synapse 37: 167-169.

Badanich KA, Adler KJ, Kirstein CL (2006). Adolescents differ from adults in cocaine conditioned place preference and cocaine-induced dopamine in the nucleus accumbens septi. Eur J Pharmacol 550: 95-106.

Barbano MF, Cador M (2007). Opioids for hedonic experience and dopamine to get ready for it. Psychopharmacology (Berl) 191: 497-506.

Beninger RJ, Ranaldi R (1992). The effects of amphetamine, apomorphine, SKF 38393, quinpirole and bromocriptine on responding for conditioned reward in rats. Behav Pharmacol 3: 155-163.

Berridge KC (1996). Food reward: brain substrates of wanting and liking. Neurosci Biobehav Rev 20: 1-25.

Berridge KC (2007). The debate over dopamine's role in reward: the case for incentive salience. Psychopharmacology (Berl) 191: 391-431.

Berridge KC (2009). 'Liking' and 'wanting' food rewards: brain substrates and roles in eating disorders. Physiol Behav 97: 537-550.

Berridge KC, Robinson TE (1998). What is the role of dopamine in reward: hedonic impact, reward learning, or incentive salience? Brain Res Brain Res Rev 28: 309-369.

Bolanos CA, Glatt SJ, Jackson D (1998). Subsensitivity to dopaminergic drugs in periadolescent rats: a behavioral and neurochemical analysis. Brain Res Dev Brain Res 111: 25-33.

Brenhouse HC, Sonntag KC, Andersen SL (2008). Transient D1 dopamine receptor expression on prefrontal cortex projection neurons: relationship to enhanced motivational salience of drug cues in adolescence. J Neurosci 28: 2375-2382.

Burns LH, Robbins TW, Everitt BJ (1993). Differential effects of excitotoxic lesions of the basolateral amygdala, ventral subiculum and medial prefrontal cortex on responding with conditioned reinforcement and locomotor activity potentiated by intra-accumbens infusions of D-amphetamine. Behav Brain Res 55: 167-183.

Burton CL, Nobrega JN, Fletcher PJ (2009). The effects of adolescent methylphenidate self-administration on responding for a conditioned reward, amphetamine-induced locomotor activity, and neuronal activation. Psychopharmacology (Berl) 208: 455-468.

Campbell JO, Wood RD, Spear LP (2000). Cocaine and morphineinduced place conditioning in adolescent and adult rats. Physiol Behav 68: 487-493.

Childress AR, Mozley PD, McElgin W, Fitzgerald J, Reivich M, O’Brien CP (1999). Limbic activation during cue-induced cocaine craving. Am J Psychiatry 156: 11-18.

Cressman VL, Balaban J, Steinfeld S, Shemyakin A, Graham P, Parisot $\mathrm{N}$ et al (2010). Prefrontal cortical inputs to the basal amygdala undergo pruning during late adolescence in the rat. J Comp Neurol 518: 2693-2709.

Cunningham MG, Bhattacharyya S, Benes FM (2002). Amygdalocortical sprouting continues into early adulthood: implications for the development of normal and abnormal function during adolescence. J Comp Neurol 453: 116-130.

Cunningham MG, Bhattacharyya S, Benes FM (2008). Increasing interaction of amygdalar afferents with GABAergic interneurons between birth and adulthood. Cereb Cortex 18: 1529-1535.

Doremus-Fitzwater TL, Varlinskaya EI, Spear LP (2010). Motivational systems in adolescence: possible implications for age differences in substance abuse and other risk-taking behaviors. Brain Cogn 72: 114-123.
Douglas LA, Varlinskaya EI, Spear LP (2003). Novel-object place conditioning in adolescent and adult male and female rats: effects of social isolation. Physiol Behav 80: 317-325.

Ellgren M, Artmann A, Tkalych O, Gupta A, Hansen HS, Hansen $\mathrm{SH}$ et al (2008). Dynamic changes of the endogenous cannabinoid and opioid mesocorticolimbic systems during adolescence: THC effects. Eur Neuropsychopharmacol 18: 826-834.

Ernst M, Pine DS, Hardin M (2006). Triadic model of the neurobiology of motivated behavior in adolescence. Psychol Med 36: 299-312.

Ernst M, Romeo RD, Andersen SL (2009). Neurobiology of the development of motivated behaviors in adolescence: a window into a neural systems model. Pharmacol Biochem Behav 93: 199-211.

Everitt BJ, Parkinson JA, Olmstead MC, Arroyo M, Robledo P, Robbins TW (1999). Associative processes in addiction and reward. The role of amygdala-ventral striatal subsystems. Ann N $Y$ Acad Sci 877: 412-438.

Fletcher PJ, Higgins GA (1997). Differential effects of ondansetron and alpha-flupenthixol on responding for conditioned reward. Psychopharmacology (Berl) 134: 64-72.

Fletcher PJ, Korth KM (1999). Activation of 5-HT1B receptors in the nucleus accumbens reduces amphetamine-induced enhancement of responding for conditioned reward. Psychopharmacology (Berl) 142: 165-174.

Fletcher PJ, Korth KM, Sabijan MS, DeSousa NJ (1998). Injections of D-amphetamine into the ventral pallidum increase locomotor activity and responding for conditioned reward: a comparison with injections into the nucleus accumbens. Brain Res 805: 29-40.

Friemel CM, Spanagel R, Schneider M (2010). Reward sensitivity for a palatable food reward peaks during pubertal developmental in rats. Front Behav Neurosci 4:39.

Geier C, Luna B (2009). The maturation of incentive processing and cognitive control. Pharmacol Biochem Behav 93: 212-221.

Kalsbeek A, Voorn P, Buijs RM, Pool CW, Uylings HB (1988). Development of the dopaminergic innervation in the prefrontal cortex of the rat. J Comp Neurol 269: 58-72.

Lanier LP, Isaacson RL (1977). Early developmental changes in the locomotor response to amphetamine and their relation to hippocampal function. Brain Res 126: 567-575.

Laviola G, Adriani W, Terranova ML, Gerra G (1999). Psychobiological risk factors for vulnerability to psychostimulants in human adolescents and animal models. Neurosci Biobehav Rev 23: 993-1010.

Lewis DA (1997). Development of the prefrontal cortex during adolescence: insights into vulnerable neural circuits in schizophrenia. Neuropsychopharmacology 16: 385-398.

Mathews IZ, McCormick CM (2007). Female and male rats in late adolescence differ from adults in amphetamine-induced locomotor activity, but not in conditioned place preference for amphetamine. Behav Pharmacol 18: 641-650.

Murschall A, Hauber W (2006). Inactivation of the ventral tegmental area abolished the general excitatory influence of Pavlovian cues on instrumental performance. Learn Mem 13: 123-126.

Olsen CM, Winder DG (2009). Operant sensation seeking engages similar neural substrates to operant drug seeking in C57 mice. Neuropsychopharmacology 34: 1685-1694.

Pears A, Parkinson JA, Hopewell L, Everitt BJ, Roberts AC (2003). Lesions of the orbitofrontal but not medial prefrontal cortex disrupt conditioned reinforcement in primates. J Neurosci 23: 11189-11201.

Petrovic P, Pleger B, Seymour B, Kloppel S, De Martino B, Critchley $\mathrm{H}$ et al (2008). Blocking central opiate function modulates hedonic impact and anterior cingulate response to rewards and losses. J Neurosci 28: 10509-10516.

Ranaldi R, Beninger RJ (1993). Dopamine D1 and D2 antagonists attenuate amphetamine-produced enhancement of responding for conditioned reward in rats. Psychopharmacology (Berl) 113: $110-118$. 
Robbins TW (1976). Relationship between reward-enhancing and stereotypical effects of psychomotor stimulant drugs. Nature 264: 57-59.

Robbins TW, Watson BA, Gaskin M, Ennis C (1983). Contrasting interactions of pipradrol, d-amphetamine, cocaine, cocaine analogues, apomorphine and other drugs with conditioned reinforcement. Psychopharmacology (Berl) 80: 113-119.

Robinson TE, Berridge KC (1993). The neural basis of drug craving: an incentive-sensitization theory of addiction. Brain Res Brain Res Rev 18: 247-291.

Robinson TE, Berridge KC (2001). Incentive-sensitization and addiction. Addiction 96: 103-114.

Schneider M, Heise V, Spanagel R (2010). Differential involvement of the opioid receptor antagonist naloxone in motivational and hedonic aspects of reward. Behav Brain Res 208: 466-472.

Schramm-Sapyta NL, Walker QD, Caster JM, Levin ED, Kuhn CM (2009). Are adolescents more vulnerable to drug addiction than adults? Evidence from animal models. Psychopharmacology (Berl) 206: 1-21.

Shram MJ, Funk D, Li Z, Le AD (2007). Nicotine self-administration, extinction responding and reinstatement in adolescent and adult male rats: evidence against a biological vulnerability to nicotine addiction during adolescence. Neuropsychopharmacology 33: 739-748.

Shram MJ, Le AD (2010). Adolescent male Wistar rats are more responsive than adult rats to the conditioned rewarding effects of intravenously administered nicotine in the place conditioning procedure. Behav Brain Res 206: 240-244.

Smith JK, Neill JC, Costall B (1997). Bidirectional effects of dopamine D2 receptor antagonists on responding for a conditioned reinforcer. Pharmacol Biochem Behav 57: 843-849.

Smith KS, Berridge KC (2007). Opioid limbic circuit for reward: interaction between hedonic hotspots of nucleus accumbens and ventral pallidum. J Neurosci 27: 1594-1605.
Spear LP (2000). The adolescent brain and age-related behavioral manifestations. Neurosci Biobehav Rev 24: 417-463.

Sutton MA, Beninger RJ (1999). Psychopharmacology of conditioned reward: evidence for a rewarding signal at D1-like dopamine receptors. Psychopharmacology (Berl) 144: 95-110.

Talbot JN, Happe HK, Murrin LC (2005). Mu opioid receptor coupling to Gi/o proteins increases during postnatal development in rat brain. J Pharmacol Exp Ther 314: 596-602.

Taylor JR, Robbins TW (1984). Enhanced behavioural control by conditioned reinforcers following microinjections of d-amphetamine into the nucleus accumbens. Psychopharmacology (Berl) 84: 405-412.

Teicher MH, Andersen SL, Hostetter Jr JC (1995). Evidence for dopamine receptor pruning between adolescence and adulthood in striatum but not nucleus accumbens. Brain Res Dev Brain Res 89: $167-172$.

Torres OV, Tejeda HA, Natividad LA, O'Dell LE (2008). Enhanced vulnerability to the rewarding effects of nicotine during the adolescent period of development. Pharmacol Biochem Behav 90: 658-663.

Wilmouth CE, Spear LP (2009). Hedonic sensitivity in adolescent and adult rats: taste reactivity and voluntary sucrose consumption. Pharmacol Biochem Behav 92: 566-573.

Winzer-Serhan UH, Chen Y, Leslie FM (2003). Expression of opioid peptides and receptors in striatum and substantia nigra during rat brain development. J Chem Neuroanat 26: 17-36.

Zakharova E, Leoni G, Kichko I, Izenwasser S (2009a). Differential effects of methamphetamine and cocaine on conditioned place preference and locomotor activity in adult and adolescent male rats. Behav Brain Res 198: 45-50.

Zakharova E, Wade D, Izenwasser S (2009b). Sensitivity to cocaine conditioned reward depends on sex and age. Pharmacol Biochem Behav 92: 131-134. 